\title{
MICROBIAL AND PERIODONTAL CHANGES ASSOCIATED WITH CONVENTIONAL VERSUS SELF LIGATING BRACKETS
}

\author{
Esam Abdullah Al-Hendi", Al-Dany A. Mohamed ${ }^{* *}$, Hussein N. El-Khalifa $^{* * *}$ and Moselhy S. Moselhy ${ }^{* * * *}$
}

\begin{abstract}
Objectives: The aim of the present study was to evaluate and compare the Microbial and periodontal changes associated with conventional versus self ligating brackets. Methods: The current randomized clinical study was conducted on a total sample of 30 orthodontic patients. The sample with mean age 16 Y. The patients were divided in to three groups, Group I: Include 10 patients treated with conventional stainless steel orthodontic brackets ligated with stainless steel ligature. Group II: Include 10 patients treated with passive self-ligating stainless steel orthodontic brackets Group III: Include 10 patients treated with active self-ligating stainless steel orthodontic brackets. Periodontal and microbial parameters were taken for each patient at baseline and at monthly interval for 6 months. The data were collected, tabulated and statistically analyzed to compare the changes within each group and among the three studied groups. Results: The results showed significant increase in microbial and periodontal parameters in the three studied groups and among the studied groups. Active self ligating brackets caused more periodontal and microbial changes than either passive self ligating or conventional brackets. Conclusion: orthodontic alignment with both conventional and self ligating brackets causes variable amounts of microbial and periodontal changes. Active self ligating brackets causes more changes in microbial, plaque and bleeding indices than either passive self ligating or conventional brackets, however, pocket depth changes were almost similar in the three groups.
\end{abstract}

\section{INTRODUCTION}

Orthodontic appliances have been linked with a higher tendency of plaque accumulation and biofilm formation. This could be attributed to the complicated nature of the appliance which make it difficult to clean and to maintain a good standard of oral hygiene ${ }^{(1)}$. This problem has a serious complication in orthodontic practice, since, the microbial activity within dental plaque could produce gingivitis, periodontitis, enamel demineralization and white spot lesions ${ }^{(2)}$. Many studies have showed that the most important etiologic factor in periodontal disease is the presence of biofilm at the gingival margin ${ }^{(2-5)}$. Periodontal diseases involve an inflammation and/or infection that results in the destruction of the supporting tissues of the teeth, including the gingiva, the periodontal ligaments, the cementum, and the alveolar bone ${ }^{(5)}$.
Fixed orthodontic appliances with the presence of brackets and ligatures create new retention areas for microbial dental plaque that is reported to be the most important etiologic factor in periodontal inflammation and enamel decalcification ${ }^{(6)}$. The methods of ligation are important factors in affecting the amount of plaque accumulated around the orthodontic fixed appliances, It has been found that, elastomeric ligation produced significantly more plaque accumulation than stainless steel ligatures ${ }^{(7)}$. Recently self ligating brackets (SLBs) systems have been introduced to the orthodontic practice, SLBs have been claimed to have many advantages, among which is eliminating the need for ligation, which, in turn, help to reduce the amount of plaque accumulation and therefore reduce the prevalence of periodontitis and enamel decalcification during orthodontic treatment ${ }^{(8-12)}$. Several studies have

\footnotetext{
* MCs Student, Demonstrator, Thamar University, Yemen Dentist, Ministry of Health, Yemen

** Professor and Chairman, Department of Orthodontics, Faculty of Dental Medicine (Boys), Al-Azhar University, Cairo, Egypt.

*** Lecturer, Department of Orthodontics, Faculty of Dental Medicine (Boys), Al-Azhar University, Cairo, Egypt.

**** Professor and Chairman, Department of Microbiology and Immunology, Faculty of Pharmacy, Boys, Cairo Al-Azhar University
} 
reported that there is a positive correlation between dental caries, periodontal disease and the degree of accumulation of the dental plaque, the consensus among many scientists regarding the microbes related to these oral diseases is as follows: The primary initiation agents of coronal caries and root caries are the mutans streptococci, particularly Streptococcus mutans (s. mutans); secondarily implicated are the Lactobacillus species ${ }^{(5-7)}$. Increased levels of S. mutans and lactobacilli are detected in the oral cavity after the bonding of orthodontic attachments (2). Fixed orthodontic appliances have been found to induce specific changes in the oral environment, such as increased plaque accumulation, raised Streptococcus mutans colonization and increases in Lactobacilli ${ }^{(2,9,13)}$.

\section{MATERIAL AND METHODS}

The current randomized clinical study was conducted on a total sample of 30 orthodontic patients randomly selected from a large pool of patients who were seeking treatment at out-patient clinic, Orthodontic Department, Faculty of Dental Medicine (boys), AL-Azhar University; Cairo. Sample size calculation was based on a power statistical analysis as follows: For an alpha error of 0.05 and power of $95 \%$, the minimum sample size required was estimated to be 30 patients, 10 patients in each arm. The patients were randomly divided into three equal groups (10 patients each) according to the type of the brackets used. Group I: Include 10 patients treated with conventional stainless steel orthodontic brackets ligated with stainless steel ligature. Group II: Include 10 patients treated with passive self-ligating stainless steel orthodontic brackets. Group III: Include 10 patients treated with stainless steel orthodontic brackets 15-19

The process of randomization and group allocation was undertaken via a computerized simple online generated randomization plan. Using online software found at the website: http://www. graphpad.com/quickcalcs/randomize2/ all patients received intensive prophylaxis procedures including scaling and gingival treatment and underwent exclusively home care instructions on oral hygiene, the patients were instructed to brush their teeth twice daily, once in the morning after breakfast and once in the evening before bedtime.125 Patient were instructed to brush a minimum of 3 minutes to ensure thorough brushing. They also were informed about the same brushing technique (Bass method technique) and prophylactic treatment two month before the base line examination to assess the patients' motivation and attitude toward home care procedures. ${ }^{14}$ During the 6 months, these subjects were not given additional information about oral hygiene. The brackets used in the present study were $0.022 \times 0.028$-inch slot self-ligating bracket Active (prodigy) (Fig.1) \& Passive (Damon Q) and conventionally ligated Roth bracket systems.

The arch wires used in the study were TruArch superelastic CuNiTi archwires for Roth conventionally ligated brackets and Damon CuNiTi archwires for active and passive SLB systems.

Plaque samples were taken at base line and at monthly interval for six months after bonding. The samples were taken by sterile paper points from the maxillary left canine, second premolar and the right central incisor and the mandibular right canine, second premolar and the left central incisor. The sequence of archwires that used for the three bracket systems were 0.014 ", 0.016 and " 0.018 " $\mathrm{Cu}$ $\mathrm{NiTi}$ arch wires. Damon $\mathrm{Cu}$ NiTi archwires were used with both types of SLBs, the Damon Q and Prodigy, while conventional bracket. Cupper NiTi arch wires were used with conventional bracket. In the first follow up visit, the archwires were removed, wires were checked for permanent deformations, and permanently deformed wire was replaced with new one.

The levelling and alignment phase lasted nearly in 6 months with appointments at monthly intervals. 
Plaque samples were taken at base line and at monthly interval for six months after bonding. For plaque sampling, the quadrant was first isolated with cotton rolls, and the facial surface of the teeth were dried with a gentle stream of air, the samples were taken by sterile paper points from the maxillary left canine, second premolar and the right central incisor and the mandibular right canine, second premolar and the left central incisor. The samples were introduced into a sterile tube (vacutainer test tube) containing thioglycolate broth. Samples were then transported within one hour to microbiology laboratory, for isolation, culturing and counting. e number of bacteria in a culture will be estimate by direct counting of the organisms and results were express as a colony forming units per sample (CFU / sample). CFU on each plate were count with a colony counter.

The following clinical parameters will be recorded at baseline before treatment and at monthly interval for 6 months after bonding;

1. Pocket probing depth. ${ }^{15}$

2. Plaque index. ${ }^{15}$

3. The presence or absence of bleeding on probing ${ }^{16}$

The Probing depth measured by a Williams's periodontal probe. The length of the probe tip at the bottom of the pocket to the gingival margin was recorded to the nearest $\mathrm{mm}$ is measured according to the Ramfjord periodontal disease index. At each tooth, measurements were taken from the mesial, distal, vestibular (buccal, labial), and midoral (lingual, palatal) tooth surfaces. At each tooth surface, the deepest site constituted the recorded probing depth.

The plaque index (PLI) was used to determine the amount of plaque on the tooth surface. According to Silness and Löe, it was assessed in the mesioficial, distofacial, and lingual surfaces of the following teeth: Maxillary right first molar, maxillary right lateral incisor, maxillary left first bicuspid, mandibular left first molar, mandibular left lateral incisor and mandibular right first bicuspid. Gingival Bleeding Index: The mouth is divided into six segments and a blunt periodontal probe was used under light finger pressure to penetrate the pocket epithelium in the following order; upper right, upper anterior, upper left, lower left, lower anterior and lower right. Reaching the highly vascular subepithelial connective tissue. If bleeding occurs within 10 seconds a positive finding is recorded and the number of positive sites is recorded and then expressed as a percentage of the number of sites examined.

The data were collected, tabulated and statistically analyzed using IBM statistical Package for Social Science (SPSS) software package for Windows, version 14, Inc., Chicago III. The data were collected, tabulated and statistically analysed using IBM Statistical Package for Social Science (SPSS) software package for Windows, version 22, Inc., Chicago, III.

Descriptive statistics of the patient's age in the three groups. The ages were ranged from 13 to 18 years with a mean age of $(16 \pm 2.2)$ years.

In concerning periodontal changes KolmogorovSmirnov and Shapiro-Wilk tests have been conducted to assess the distribution of data in the three groups. For the pocket depth (PD) and bleeding index (BI), there were significant differences in the three groups, indicating that the data were abnormally distributed, therefore non parametric statistical tests were performed for these two variables. At contrast, no significant differences were found in the three groups for the plaque index (PI) indicating that the data were normally distributed, therefore parametric statistical tests were performed for this variable.

In concerning the bacterial changes, the $\log 10$ transformation was applied to the microbiologic data for normalizing the distribution and stabilizing 


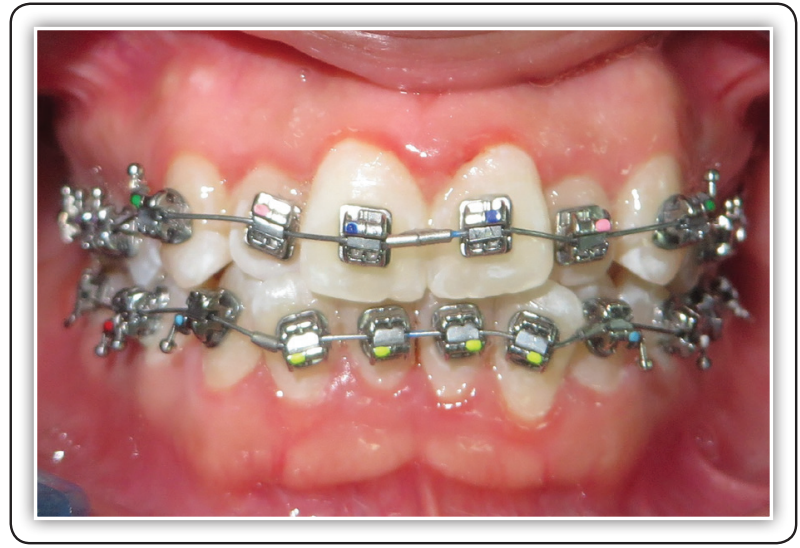

Fig. (1) Active SLBs (Prodigy)

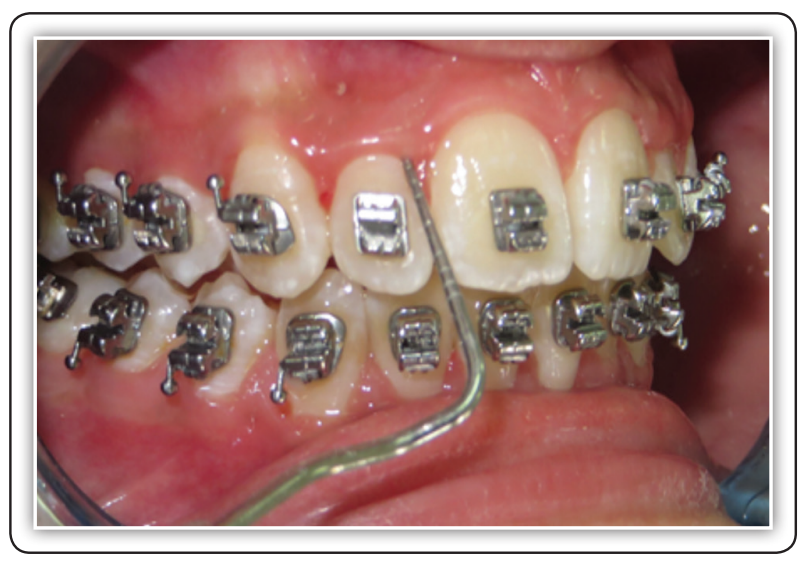

Fig. (3) Periodontal pocket depth measurement.

the variance. Kolmogorov-Smirnov and ShapiroWilk tests have been conducted to assess the distribution of data in the three groups showing that there were no significant differences in the all data in the three groups, indicating that the data were normally distributed, therefore parametric statistical tests were performed for bacterial count.

\section{RESULTS}

The present study has been conducted on thirty orthodontic patients divided into 3 equal groups; group I (Conventional Brackets), group II (Passive SLBs) and group III (Active SLBs). All patients in the study have completed their treatment until the research objectives have been achieved. The patients will then continue their treatment up to

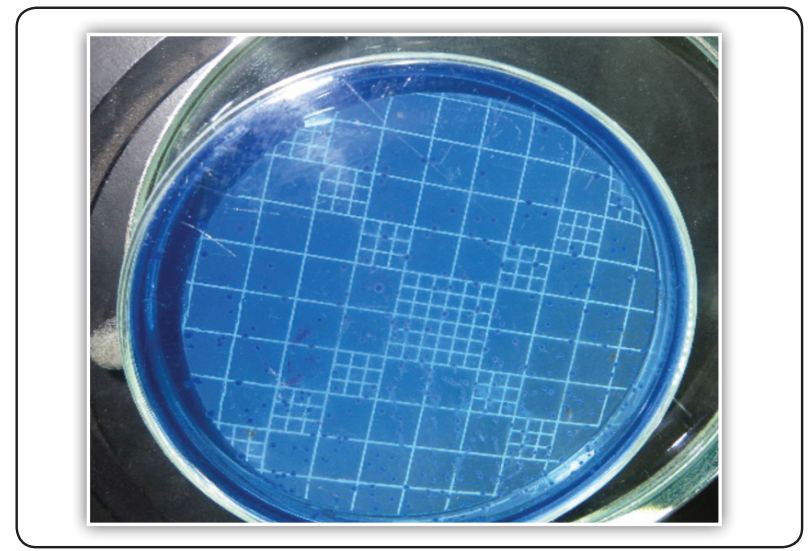

Fig. (2) Total colony count of streptococci mutans.

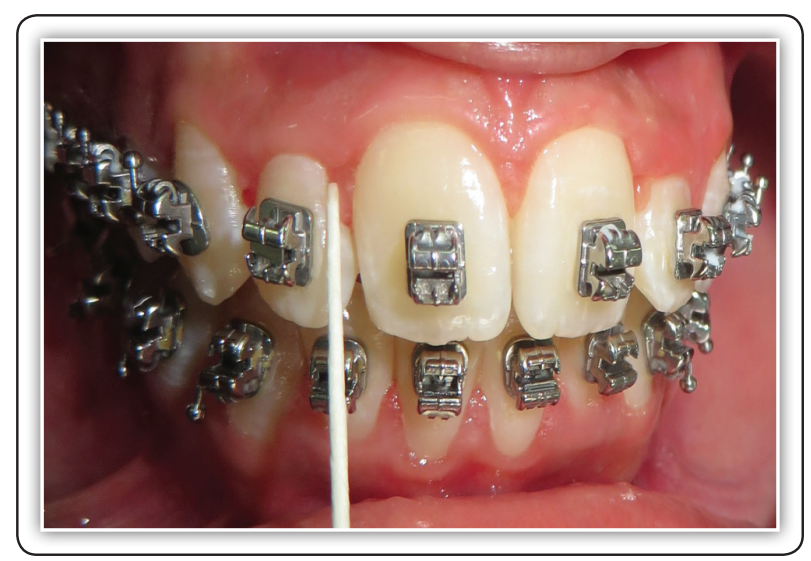

Fig. (4) Dental plaque assessment

finishing according to the predetermined treatment plans. The results have the results have shown that; the periodontal indices significantly increased during treatment within each group. Among group comparisons have shown that, the plaque and bleeding indices significant increase in the active group than the conventional and passive SLBs, while the pocket depth has shown no significant changes among the three groups. In addition, the S. mutans and lactobacilli counts have shown statistically significant increase within each group. Concerning among groups, the greatest numbers of bacterial counts were found in the active self ligating brackets group and the fewest bacterial counts were found in conventional brackets group. These findings suggest that; orthodontic alignment 
with both conventional and self ligating brackets causes variable changes in periodontal parameters and microbial counts. Active self ligating brackets caused more periodontal and microbial changes than either passive self ligating or conventional brackets.
Conventional and passive SLBs bracket types are preferred over the active brackets in reducing the risk for periodontal and microbial changes during the alignment phase of orthodontic treatment.

TABLE (1) Descriptive statistics and test of significance (Friedman test) within group and (Kruskal-Wallis test) for the effect of treatment on PD among groups.

\begin{tabular}{|c|c|c|c|c|c|c|c|c|}
\hline \multirow{2}{*}{ Time } & \multicolumn{2}{|c|}{ Group I } & \multicolumn{2}{|c|}{ Group II } & \multicolumn{2}{|c|}{ Group III } & \multirow{2}{*}{$\mathbf{X}^{2}$} & \multirow{2}{*}{ P value } \\
\hline & Median & IQR & Median & IQR & Median & IQR & & \\
\hline T0 & 1.2 & 0.37 & 1.1 & 0.2 & 1 & 0.25 & 0.124 & 0.94 \\
\hline T1 & $1^{\mathrm{a}}$ & 0.2 & $1.25^{\mathrm{b}}$ & 0.1 & $1^{\mathrm{a}}$ & 0.1 & 7.4 & $0.025^{*}$ \\
\hline $\mathbf{T} 2$ & 1.3 & 0.1 & 1.4 & 0.3 & 1.2 & 0.2 & 1.127 & 0.569 \\
\hline T3 & $1.5^{*}$ & 0.2 & $1.5^{*}$ & 0.2 & $1.3^{*}$ & 0.4 & 0.225 & 0.894 \\
\hline T4 & $1.5^{*}$ & 0.2 & $1.7 *$ & 0.3 & $1.5^{*}$ & 0.3 & 3.553 & 0.169 \\
\hline T5 & $1.3^{*}$ & 0.4 & $1.75^{*}$ & 0.5 & $1.5^{*}$ & 0.5 & 5.189 & 0.075 \\
\hline T6 & $1.7 *$ & 0.3 & $1.8^{*}$ & 0.5 & $1.7 *$ & 0.4 & 5.066 & 0.079 \\
\hline $\mathbf{X}^{2}$ & \multicolumn{2}{|c|}{55.98} & \multicolumn{2}{|c|}{48.022} & \multicolumn{2}{|c|}{49.059} & & \\
\hline$P$ value & \multicolumn{2}{|c|}{$<0.001$} & \multicolumn{2}{|c|}{$<0.001$} & \multicolumn{2}{|c|}{$<0.001$} & & \\
\hline
\end{tabular}

* Significant when $p \leq 0.05$. Median with the same letters do not differ statistically.

TABLE (2) The comparison of Plaque index within each group by using (post hock test) and between groups by using (one-way ANOVA)

\begin{tabular}{|c|c|c|c|c|c|c|c|}
\hline \multirow{2}{*}{ Time } & \multicolumn{2}{|c|}{ Group I } & \multicolumn{2}{|c|}{ Group II } & \multicolumn{2}{|c|}{ Group III } & \multirow{2}{*}{ P value } \\
\hline & Mean & \pm SD & Mean & \pm SD & Mean & $\pm \mathrm{SD}$ & \\
\hline T0 & .39 & .14 & .53 & .30 & .35 & .23 & 0.209 \\
\hline T1 & .45 & .13 & .57 & .25 & $.65^{*}$ & .23 & 0.128 \\
\hline T2 & $.73 *$ & .19 & $.77 *$ & .27 & $.87 *$ & .24 & 0.385 \\
\hline T3 & $.92 * a$ & .21 & $.94^{* a}$ & .24 & $1.20 * \mathrm{~b}$ & .19 & $0.014 *$ \\
\hline T4 & $1.00 * \mathrm{a}$ & .23 & $1.04 * \mathrm{ab}$ & .23 & $1.28^{* \mathrm{~b}}$ & .30 & $0.042 *$ \\
\hline T5 & $1.14^{* a}$ & .23 & $1.15^{* \mathrm{a}}$ & .22 & $1.59^{* \mathrm{~b}}$ & .24 & $<0.001 *$ \\
\hline T6 & $1.21^{* a}$ & .16 & $1.30^{* a}$ & .32 & $1.68^{* b}$ & .25 & $0.001 *$ \\
\hline P value & \multicolumn{2}{|c|}{$<0.001$} & \multicolumn{2}{|c|}{$<0.001$} & \multicolumn{2}{|c|}{0.001} & \\
\hline
\end{tabular}

* Significant when $p \leq 0.05$. Median with the same letters do not differ statistically. 
TABLE (3) Descriptive statistics and test of significance (Friedman test) within group and (Kruskal-Wallis test) for the effect of treatment on BI among groups.

\begin{tabular}{|c|c|c|c|c|c|c|c|c|}
\hline \multirow{2}{*}{ Time } & \multicolumn{2}{|c|}{ Group I } & \multicolumn{2}{|c|}{ Group II } & \multicolumn{2}{|c|}{ Group III } & \multirow{2}{*}{$\mathbf{X}^{2}$} & \multirow{2}{*}{ Pvalue } \\
\hline & Median & IQR & Median & IQR & Median & IQR & & \\
\hline T0 & 0 & 0.17 & 0.17 & 0.21 & 0.17 & 0.17 & 0.887 & 0.887 \\
\hline $\mathbf{T 1}$ & 0.17 & 0 & 0.17 & 0.04 & 0.17 & 0 & 0.382 & 0.826 \\
\hline $\mathbf{T} 2$ & $0.33^{\mathrm{a}}$ & 0.16 & $0.33^{\mathrm{a}}$ & 0.2 & $0.5^{\mathrm{b}}$ & 0.25 & 8.752 & $0.013^{*}$ \\
\hline T3 & $0.5^{* \mathrm{a}}$ & 0.17 & $0.5^{* \mathrm{a}}$ & 0.17 & $0.67 * \mathrm{~b}$ & 0.08 & 15.029 & $0.001 *$ \\
\hline T4 & $0.5^{* \mathrm{a}}$ & 0.17 & $0.42 * \mathrm{a}$ & 0.21 & $0.67 * \mathrm{~b}$ & 0.25 & 13.684 & $0.001^{*}$ \\
\hline T5 & $0.5^{* \mathrm{a}}$ & 0.34 & $0.5^{* \mathrm{a}}$ & 0.17 & $0.83 * \mathrm{~b}$ & 0.25 & 15.792 & $<0.001^{*}$ \\
\hline T6 & $0.67 * \mathrm{a}$ & 0.17 & $0.67 * \mathrm{a}$ & 0.04 & $0.83^{* \mathrm{~b}}$ & 0.17 & 17.831 & $<0.001^{*}$ \\
\hline $\mathbf{X}^{2}$ & \multicolumn{2}{|c|}{52.51} & \multicolumn{2}{|c|}{48.023} & \multicolumn{2}{|c|}{48.718} & & \\
\hline P value & \multicolumn{2}{|c|}{$<0.001 *$} & \multicolumn{2}{|c|}{$<0.001 *$} & \multicolumn{2}{|c|}{$<0.001^{*}$} & & \\
\hline
\end{tabular}

* Significant when $p \leq 0.05$. Median with the same letters do not differ statistically.

TABLE (4) Descriptive statistics and test of significance (ANOVA) for the S. mutans count ( $\log 10)$ within group and among groups.

\begin{tabular}{|c|c|c|c|c|c|c|c|}
\hline \multirow{2}{*}{ Time } & \multicolumn{2}{|c|}{ Group I } & \multicolumn{2}{|c|}{ Group II } & \multicolumn{2}{|c|}{ Group III } & \multirow{2}{*}{$P$ value } \\
\hline & Mean & \pm SD & Mean & \pm SD & Mean & $\pm \mathrm{SD}$ & \\
\hline T0 & 5.24 & .08 & 5.25 & .12 & 5.25 & .12 & 0.939 \\
\hline T1 & 5.26 & .09 & 5.31 & .07 & 5.32 & .08 & 0.165 \\
\hline $\mathrm{T} 2$ & 5.42 & .29 & 5.37 & .06 & $5.40 *$ & .07 & 0.816 \\
\hline T3 & $5.33^{\mathrm{a}}$ & .11 & 5.42 *ab & .06 & $5.43 * \mathrm{~b}$ & .08 & $0.045^{*}$ \\
\hline T4 & 5.46 & .25 & $5.45^{*}$ & .06 & $5.48 *$ & .08 & 0.961 \\
\hline T5 & 5.66 & .39 & $5.49 *$ & .04 & $5.52 *$ & .07 & 0.234 \\
\hline T6 & $5.45 *$ & .07 & $5.53 * a$ & .04 & $5.57 * \mathrm{a}$ & .08 & $0.001 *$ \\
\hline P value & \multicolumn{2}{|c|}{0.001} & \multicolumn{2}{|c|}{0.007} & \multicolumn{2}{|c|}{0.018} & \\
\hline
\end{tabular}

* Significant when $p \leq 0.05$. Median with the same letters do not differ statistically.

TABLE (5) Descriptive statistics and test of significance (ANOVA) for the lactobacilli count (log10) within group and among groups.

\begin{tabular}{|c|c|c|c|c|c|c|c|}
\hline & \multicolumn{2}{|c|}{ Group I } & \multicolumn{2}{|c|}{ Group II } & \multicolumn{2}{|c|}{ Group III } & \multirow{2}{*}{ P value } \\
\hline & Mean & \pm SD & Mean & $\pm \mathrm{SD}$ & Mean & \pm SD & \\
\hline T0 & 5.09 & .09 & 5.01 & .36 & 5.12 & .12 & 0.549 \\
\hline T1 & 5.19 & .09 & 5.16 & .06 & 5.21 & .07 & 0.348 \\
\hline $\mathbf{T} 2$ & $5.22^{\mathrm{a}}$ & .07 & $5.22^{\mathrm{ab}}$ & .07 & $5.33 * \mathrm{~b}$ & .08 & $0.002 *$ \\
\hline T3 & $5.30 *$ & .11 & 5.28 & .07 & $5.37 *$ & .08 & 0.132 \\
\hline T4 & $5.31 * \mathrm{a}$ & .13 & $5.33^{\mathrm{ab}}$ & .09 & $5.55^{\mathrm{b}}$ & .31 & $0.021 *$ \\
\hline T5 & $5.34 * \mathrm{a}$ & .12 & $5.38^{\mathrm{a}}$ & .06 & $5.61^{\mathrm{b}}$ & .28 & $0.005^{*}$ \\
\hline T6 & $5.40 * \mathrm{a}$ & .08 & $5.44 * \mathrm{a}$ & .05 & $5.54 * \mathrm{~b}$ & .05 & $<0.001 *$ \\
\hline$P$ value & \multicolumn{2}{|c|}{0.027} & \multicolumn{2}{|c|}{0.003} & \multicolumn{2}{|c|}{$<0.001$} & \\
\hline
\end{tabular}

* Significant when $p \leq 0.05 . \quad$ Median with the same letters do not differ statistically. 


\section{DISCUSSION}

The plaque retention is a frequent problem associated with orthodontic treatment due to increase in the number of retentive sites for plaque accumulation and biofilm formation. The microbial activity within dental plaque is responsible for many complications, such as gingivitis, periodontitis, white spot lesions and caries around the orthodontic attachments ${ }^{(2)}$. Therefore, the benefits derived from improving tooth alignment, esthetic and occlusal function are at least temporarily offset by these complications which detract from the facial esthetics and compromise the treatment results. This study aimed to compare the effects of using self ligating bracket and conventional bracket on the microbial count and periodontal status ${ }^{(5)}$.

The results of the current study have shown a statistically non-significant difference in the pocket depth among the three groups. These results are in accordance with several studies, which found that no significant changes in the pocket depth values among patients treated with self ligating or conventional edgewise brackets, therefore, the bracket type would not be considered a risk factor in progression of pocket depth during treatment. The results of the present study have shown a statistically significant increase in plaque accumulation in the active self ligating group than both conventional and passive self ligating groups at T3, T4, T5 and T6. The results of the current study have shown no significant differences between conventional and passive groups. These results are in agreement with Mauricio et al ${ }^{(12)}$, who found no significant differences between passive self ligating and conventional brackets. 162,165-169 Compared the effect of Self Ligating and conventional bracket systems on the buccal bone level and thickness during orthodontic treatment. In contrast, the results of the current study disagree with the findings of Fatma et al ${ }^{(17)}$, who found significant increase in the plaque index in the passive group than in conventional group. This disagreement may be attributed to the difference of manufacturing company of different brackets types used in study.

The results of the current study have shown a statistically significant increase in bleeding index in the active self ligating brackets group than the other two groups at T2, T3, T4, T5 and T6. The results of the current study have shown no significant difference in bleeding index between conventional and passive self ligating brackets group, these results support those found with study ${ }^{(18)}$ which reported no significant differences bleeding index between conventional and passive self ligating brackets group. Searching the literature up to March 2017 has revealed no study compared gingival bleeding index changes among active self ligating, passive self ligating and conventional bracket groups.163,164,166,167 In the current study, the among group comparison have shown a statistically significant increase in S. mutans count in the active group when compared with conventional group at T3and significant increase in the active self ligating brackets group and passive self ligating brackets group when compared with conventional brackets group at T6 These results are in accordance with Aguinaldo et al $^{(19)}$, but contrasting, the results of Leonard et al, ${ }^{(20)}$ may be because the difference in the method of assessment, time intervals and bracket material (esthetic brackets). the results of the current study have shown a statistically significant increase in the active self ligating brackets group when compared with conventional and passive self ligating brackets groups at T2, T4, T5 and T6. Searching the literature up to March 2017 has revealed no study compared lactobacilli counts in active, passive and conventional bracket groups.

\section{CONCLUSION}

\section{Concerning the periodontal changes:}

1. In general, orthodontic alignment with both conventional and self ligating brackets causes variable amounts of periodontal changes. 
2. Active self ligating brackets causes more changes in plaque and bleeding indices than either passive self ligating or conventional brackets, however, pocket depth changes were almost similar in the three groups.

3. The conventional brackets ligated with steel ligation and passive SLBs are preferred over the active SLBs in reducing the risk for periodontal complication during the alignment phase of orthodontic treatment.

\section{Concerning the microbial changes:}

1. In general, orthodontic alignment with both conventional and self ligating brackets causes considerable amounts of microbial changes.

2. Active self-ligating brackets induce more bacterial colonization followed by the passive selfligating brackets and the fewest bacterial counts were recorded for the conventional brackets.

\section{REFERENCES}

1. Alves d, Borges M, Nouer D. Periodontal and microbiologic evaluation of 2 methods of archwire ligation: Ligature wires and elastomeric rings. Am J Orthod Dentofac Orthop. 2008; 134:506-512.

2. Nikki E. Atack, Jonathan R. Sandy and M. Periodontal and Microbiological Changes Associated with the Placement of Orthodontic Appliances. J Periodontol. 1996; 67:78-85.

3. Anand M, Turpin D, Jumani K, Spiekerman C, Huang G. Retrospective investigation of the effects and efficiency of self-ligating and conventional brackets. Am J Orthod Dentofac Orthop. 2015; 148:67-75.

4. Aas J, Paster B, Stokes L, Olsen I, Dewhirst F. Defining the Normal Bacterial Flora of the Oral Cavity Defining the Normal Bacterial Flora of the Oral Cavity. J Clin Microbiol. 2005; 43:5721-5732.

5. Aas J , Paster B, Stokes L, Olsen I, Dewhirst F. Defining the Normal Bacterial Flora of the Oral Cavity Defining the Normal Bacterial Flora of the Oral Cavity. J Clin Microbiol. 2005;43:5721-5732.

6. Jurela A, Repic D, Pejda. The effect of two different bracket types on the salivary levels of $\mathrm{S}$ mutans and $\mathrm{S}$ sobrinus in the early phase of orthodontic treatment. Angle Orthod. 2013; 83:140-145.
7. Brusca MI, Chara O, Sterin-Borda L, Rosa AC. Influence of different orthodontic brackets on adherence of microorganisms in vitro. Angle Orthod. 2007; 77:331-336.

8. Anhoury P, Nathanson D, Hughes C, Socransky S, Feres M, Chou L. Microbial Profile on Metallic and Ceramic Bracket Materials. Angle Orthod. 2002; 72:338-343.

9. Euler A, Maria G, Rita P, Cople M. Are self-ligating brackets related to less formation of Streptococcus mutans colonies? A systematic review. Dent Press J Orthod. 2014; 19:60-68.

10. Moolya N, Sharma R, Shetty A, Gupta N, Gupta A, Jalan V. Orthodontic bracket designs and their impact on microbial profile and periodontal disease: A clinical trial. J Orthod Sci. 2014; 3:125.

11. Pithon M, dos Santos R, Nascimento L, Ayres A, Alviano D, Bolognese A. Do self-ligating brackets favor greater bacterial aggregation? Brazilian J Oral Sci. 2011; 10:208-212.

12. Van G, Quirynen M, Teughels W, Coucke W, Carels C. Influence of bracket design on microbial and periodontal parameters in vivo. J Clin Periodontol. 2007; 34:423-431.

13. Cardoso M, Saraiva P, Maltagliati L. Alterations in plaque accumulation and gingival inflammation promoted by treatment with self-ligating and conventional orthodontic brackets. Dental Press J Orthod. 2015; 20:35-41.6.

14. Mills B. Your role before, during, and after orthodontic treatment. national Mag Dent Hyg Prof. 2014;(June).

15. Ramfjord S. The Periodontal Disease Index (PDI). J Periodontol. 1967; 38:602-610.

16. Armitage G. Development of a Classification System for Periodontal Diseases and Conditions. Ann Periodontol. 1999; 4:1-6.

17. Uzuner F, Kaygisiz E, Çankaya Z. Effect of the bracket types on microbial colonization and periodontal status. Angle Orthod. 2014; 84:1062-1067.

18. Shrestha B, Jin X, Chen L, Shrestha R. Comparative Study of Periodontal Status of Early Orthodontic Subjects treated with Self-ligating Brackets vs Conventional Edgewise Brackets. J Indian Orthod Soc. 2014; 48:365-369.10.

19. Garcez A, Suzuki S, Ribeiro M, Mada E, Freitas A, Suzuki H. Biofilm retention by 3 methods of ligation on orthodontic brackets: a microbiologic and optical coherence tomography analysis. Am J Orthod Dentofacial Orthop. 2011; 140: e193-8.

20. Do N, Pithon M, Dos S. Colonization of Streptococcus mutans on esthetic brackets: Self-ligating vs conventional. Am J Orthod DentofacOrthop.2013; 143:72-77. 